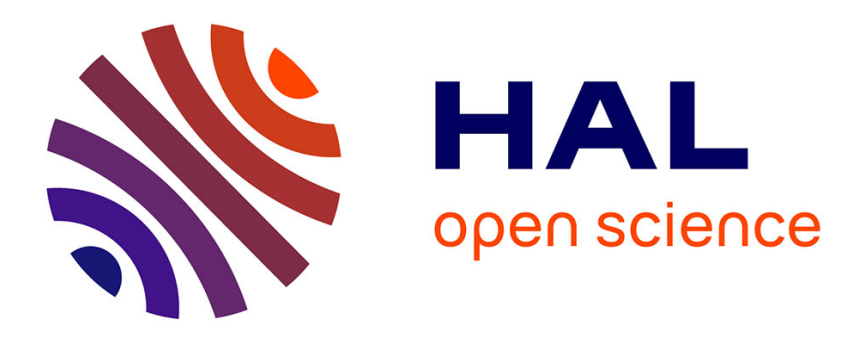

\title{
Stem Cells and the Temporal Boundaries of Development: Toward a Species-Dependent View
}

\author{
Lucie Laplane
}

\section{To cite this version:}

Lucie Laplane. Stem Cells and the Temporal Boundaries of Development: Toward a SpeciesDependent View. Biological Theory, 2011, 6 (1), pp.48-58. 10.1007/s13752-011-0009-z . halshs00759324

\section{HAL Id: halshs-00759324 \\ https://shs.hal.science/halshs-00759324}

Submitted on 16 Feb 2013

HAL is a multi-disciplinary open access archive for the deposit and dissemination of scientific research documents, whether they are published or not. The documents may come from teaching and research institutions in France or abroad, or from public or private research centers.
L'archive ouverte pluridisciplinaire HAL, est destinée au dépôt et à la diffusion de documents scientifiques de niveau recherche, publiés ou non, émanant des établissements d'enseignement et de recherche français ou étrangers, des laboratoires publics ou privés. 


\title{
Stem Cells and the Temporal Boundaries of Development: Toward a Species-Dependent View
}

\author{
Lucie Laplane
}

Received: 21 May 2011/Accepted: 7 July 2011/Published online: 8 November 2011

(C) Konrad Lorenz Institute 2011

\begin{abstract}
The tacit standard view that development ends once reproductive capacity is acquired (reproductive boundary, or "RB," thesis) has recently been challenged by biologists and philosophers of biology arguing that development continues until death (death boundary, or "DB," thesis). The relevance of these two theses is difficult to assess because the fact that there is no precise definition of development makes the determination of its temporal boundaries problematic. Taking into account this difficulty, this article tries to develop a new species-dependent perspective on temporal boundaries of development. This species-dependent account stands against both RB and DB theses since neither of them reflects the differences between species in the temporality of their development. In this perspective, I propose to use stem cells as a tool to analyze (1) the different developmental capacities of an organism during its life; and (2) the different developmental temporal capacities between species. In particular, I will show that stem cells enable four distinct temporal developmental patterns to be distinguished, i.e., four distinct temporal boundaries of development in the living. I show how these four patterns can be interpreted differently depending on the perspective one has on the definition of development.
\end{abstract}

\section{Laplane}

Department of Philosophy, University Paris Ouest Nanterre La Défense, Nanterre, France

L. Laplane $(\bowtie)$

Department of Human Sciences, Gustave Roussy Hospital, Villejuif, France

e-mail: laplanettelucie@gmail.com
Keywords Asexual reproduction · Boundary · Definition · Development · Differentiation · Division . Regeneration $\cdot$ Stem cells

This article mainly focuses on the question of the temporal boundaries of development: When does development begin and end? Currently, the debate on the temporal boundaries of development particularly concerns the end of development and is structured around two main theses. According to the most classical one, development ends when the organism is sexually mature (i.e., capable of reproduction): I will call it the RB thesis (for reproductive boundary). Recently, biologists and philosophers have challenged the validity of the RB thesis, arguing that development is a process that lasts throughout life, only ending with death: I will call it the DB thesis (for death boundary). The definition of development by Laubichler and Maienshein (2005) offers a good example of this DB thesis:

Development in biology refers to the process of growth and differentiation that is characteristic of living organisms. It describes the continuous changes during the life cycle of individual organisms from the early stage of a single cell until death. (p. 570)

The first difficulty encountered when one wants to determine the temporal boundaries of development is the vagueness of the definition of development. Development is so imprecisely defined, if at all, that it is almost impossible to assess what processes and mechanisms are or are not part of development. However, despite this difficulty and whatever the definition of development is, there is a certainty that development differs from one species to another. On this ground, this article argues against the presumed universality of both the RB and $\mathrm{DB}$ theses and 
develops a species-dependent account of the temporality of development using stem cells as a tool. The species level is justified by the fact that species is the main level of knowledge in biology, in particular, concerning development. Individual differences are ignored as irrelevant and higher taxa are represented by model organisms that are laboratory species. I will first address the problem of the definition of development and its impacts on the issue of temporal boundaries. Then I will present stem cells, a parsimonious and valuable tool to develop a speciesdependent perspective on the temporality of development. I will show that different types of stem cells bearing different developmental abilities are specific to different periods of life, and this in a species-dependent way. This analysis will lead to the distinction of four temporal developmental patterns (TDP), that is, four distinct temporalities of development depending on species developmental capacities. Finally, I will analyze the temporal boundaries described by these TDP.

\section{The Vagueness of the Definition of Development}

The greatest difficulty encountered when studying the issue of the temporality of development is the vagueness of the definition of development. Indeed, to determine when development begins and ends, one must define what counts and what does not count as development. Thus, while defining development may be beyond the scope of this article, it is necessary to address the problem. I will first address it in a fairly general way and suggest some possible solutions. Then, I will examine its consequences on the issue of the temporal boundaries of development, showing that the vagueness of the definition of development prohibits the interpretation of biological data. This will lead me to the search for a different perspective on the question of the temporality of development, an approach that avoids these pitfalls.

As shown by Jason Scott Robert in his book Embryology, Epigenesis, and Evolution: Taking Development Seriously (2004a), development is an important concept for many different fields including developmental biology, evolutionary biology, biomedicine, and behavioral biology, but also for public discourses (Love 2006) and legislation (Hauskeller 2005; Marks 2010). All these disciplines are involved in its definition and give specific meanings to what development is. EvoDevo tends to produce a definition of development that is most often restricted to embryogenesis. For instance, in his article on evolutionary developmental biology, the four examples given by Robert "in order to illustrate the complex interplay between development and evolution" (2002, p. 599) are all embryonic. Similarly, developmental biology most often limits development to the segregation of the distinct cell types and the production of the organization plan. In contrast, biomedicine produces a much broader definition of development in its taking into account of adult physiology. Thus, development is a "boundary concept" (Star and Griesemer 1989), that is to say, it is a concept used by very different communities in heterogeneous contexts. This may require the preservation of a relatively vague and flexible definition to allow communication between culturally distinct communities (on the defense of the fuzzy concept in biology, see Löwy 1991, 1992; Crist and Tauber 1999; Rheinberger 2000).

Boundary objects are objects that are both plastic enough to adapt to local needs and the constraints of the several practices employing them, yet robust enough to maintain a common identity across sites. They are weakly structured in common use, and become strongly structured in individual-site use. These objects may be abstract or concrete. They have different meanings in different social worlds but their structure is common enough to more than one world to make them recognizable, a means of translation. (Star and Griesemer 1989, p. 393)

However, the current fuzziness around the concept of development raises several questions. First, before taking the need of a vague definition for granted, it would be important to study the different definitions of development and to verify that there are no hidden homonyms among them. It is not excluded that some definitions of development refer to resolutely distinct objects. In these cases, it would be important to distinguish among these homonyms. Second, is the current unspecified definition of development really useful? If not, should we really keep on using this concept?

Three options can be considered to remove the ambiguities surrounding the definition of development. First, the concept of development could be abandoned in favor of more precise notions such as "cleavage," "gastrulation," "cellular differentiation," "organogenesis," and so on (see Pradeu 2011, this issue). Second, development could be defined more precisely so as to clearly distinguish what is development from what is not. This could be the most satisfactory solution but it is also the most difficult one to achieve. It would require a tremendous amount of work (which would probably be very beneficial) but mostly it would require reaching a consensus (which is unfortunately highly unlikely). Third, the referential of the concept of development could be specified for each use in a sort of binominal nomenclature (e.g., embryonic development) that would clarify the definition of development that is used. This could be the most reasonable solution given that it would not affect its status of boundary object. 
A direct consequence of the vagueness of the definition of development is that it makes it difficult to determine its beginning and its end, and also to criticize the DB thesis based on biological data: A huge amount of biological phenomena can easily be absorbed as part of development and give arguments for the persistence of development throughout life. Therefore, the DB thesis has, today, a key advantage compared to the RB thesis. Nevertheless, a distinction must be made when discussing the DB thesis: It can be interpreted in two ways. A strong interpretation of the DB thesis (SDB thesis) posits that development only ends with death because the same mechanisms and processes last throughout life. The weak interpretation (WDB thesis) posits that development lasts throughout life because it is a complex and heterogeneous phenomenon that involves a set of various mechanisms and processes occurring by stages throughout life. Only the WDB thesis benefits from the vagueness of the definition. However, because of the current state of the definition of development and of the WDB thesis, we must be very cautious on the interpretation of the biological data. In particular, regarding the interpretation of the biological differences occurring between periods of the life of an organism (if any), I will keep the two following interpretations open: Either one considers that these differences belong to different types of development occurring at different stages of life (i.e., the development is multiphasic) or one considers that the cessation of some processes and mechanisms distinguish a development period from a period without development (i.e., the development is monophasic, it begins and ends with these processes). One can also consider these differences as an argument for abandoning the concept of development. Obviously, I will not follow this interpretation because it would prohibit any investigation of the temporality of development.

In conclusion, the current concept of development critically lacks a precise definition, which makes difficult (a) the task of assessing the temporal boundaries of development, and (b) the criticism of the WDB thesis. Despite these difficulties, there is a trivial argument against both the RB and the DB (SDB as well as WDB) theses. Both are supposedly universal whereas the diversity of developmental processes and mechanisms among species is irrefutable. Species have different capacities for growth, regeneration, or reproduction; developmental processes (whatever they may be) can last for varying lengths of time depending on species. A good account of the temporality of development should report this temporal diversity among species and this is what I will aim to do: propose a species-specific description of the temporality of development (see also Théry 2011, this issue).

\section{Stem Cell Classifications}

In this section, I will define stem cells and show how the different types of stem cells can be taken as a criterion to analyze the temporality of development. First, stem cells are strongly related to developmental abilities: The more the potential of stem cells is important, the more the developmental potential of the organ and/or organism is high, and vice versa. Second, the description of the different types of stem cells (and different developmental abilities to which they are related) directly implies a temporal perspective.

In order to use stem cells as a means to analyze the temporality of development, it is necessary to define them strictly. As stem cell definition is often a matter of controversy, it is of particular importance to remove all ambiguities. The common properties ascribed to stem cells are (a) the capacity to self-renew, and (b) the ability to differentiate into two or more cell types. However, this definition raises many difficulties. Those properties have been criticized for being too inclusive or too exclusive. First, both criteria appear too inclusive for the following reasons: (a) some non stem cells like lymphocytes can also self-renew (Mikkers and Frisen 2005), and (b) some non stem cells like many progenitors can also differentiate into two or more different cell types (Lander 2009). A possible response to this problem of inclusivity is to consider that stem cells possess the two properties whereas (a) progenitors do not self-renew (or not for long anyway), and (b) lymphocytes do not differentiate into different cell types. This is, for example, the position of Seaberg and van der Kooy (2003, p. 128), who advocate maintaining the difference between stem cells and progenitors: "It is our contention that a cell must demonstrate unlimited selfrenewal, multipotentiality and, crucially, the maintenance of these properties," whereas "by contrast, progenitors are proliferative cells with a limited capacity for self-renewal" (p. 125). However, then the problem is that together those two properties used to define stem cells become too exclusive: (1) some stem cells, such as mammal embryonic stem (ES) cells, do not self-renew, and (2) "there are unipotent self-renewing cells, most notably germ-line stem cells, which most scientists would argue are obvious stem cells" (Mikkers and Frisen 2005, p. 2715). One possibility to resolve this problem is to consider that germinal stem cells, ES cells, and all the cells that do not share the two properties are not real stem cells. A few scientists follow this path but they never work on embryonic or germinal stem cells. This solution does not lead to a consensus (on stem cell definition debates see also: Blau et al. 2001; Loeffler and Roeder 2002; Zipori 2004, 2005, 2006; Leychkis et al. 2009; Zipori 2009). The other possibility, which is the most common one, to resolve these difficulties 
relating to the definition of stem cells, consists in introducing distinctions between stem cells and classifying them according to these two definitional properties (i.e., potential of differentiation and self-renewal).

The most common classification is based on the potential of differentiation. Biologists distinguish four types of stem cells according to this criteria: There are totipotent stem cells (able to give all the cell types of an organism, including extraembryonic ones), pluripotent stem cells (able to give all the cell types of an organism except the extraembryonic ones), multipotent stem cells (able to differentiate into two or more cell types), and unipotent stem cells (able to differentiate into only one cell type) (Alison et al. 2002). As will be discussed later, some of these types of stem cells are specific to some species. In particular, the distinction between totipotent and pluripotent stem cells obviously applies only to species whose development requires extraembryonic annexes. However, for every species, these different stem cells represent highly different developmental abilities for the systems (tissues, organs, and/or organisms) to which they belong: A living organism cannot develop from unipotent and multipotent stem cells whereas it can with totipotent stem cells.

The second property of stem cells, i.e., the ability to self-renew, is also used as a way to classify stem cells. However, self-renewal is a subject of controversy. First of all, the concept of self-renewal takes on different meanings depending on the biologist. For some of them it means that the cell is able to give rise to new stem cells for an unlimited time (extensive self-renewal below), whereas for others self-renewal is just "the process by which a stem cell divides to generate one (asymmetric division) or two (symmetric division) daughter stem cells with developmental potentials that are indistinguishable from those of the mother cell" (Molofsky et al. 2004, p. 700). Second, it is very difficult to determine whether the capacity for self-renewal should be attributed to a variety of stem cells: ES cells do not extensively selfrenew in vivo but they do extensively self-renew in vitro; conversely, tissue-specific stem cells do extensively selfrenew in vivo (note that the possibility that stem cells eventually lose their ability to self-renew during aging is also an open question) but they are often very difficult to maintain in the stem state in vitro. Thus, using the concept of self-renewal to distinguish different types of stem cell seems quite ambiguous.

Shostak (2006) offers an alternative way to account for differences in stem cell renewal. He distinguishes "steadystate stem cells" from "emergent stem cells." The difference between the two categories lies mainly in the rate of division: Steady-state stem cells divide very rarely whereas emergent stem cells divide at a higher rate. In the same vein, Morrison and his colleagues (Molofsky et al. 2004; Morrison and Kimble 2006; Levi and Morrison 2008) distinguish stem cells based on symmetric and asymmetric divisions: Symmetric divisions "expand stem-cell pools" whereas asymmetric divisions keep them. This distinction is very similar to that of Shostak: Expansion is what Shostak refers to with his "emergent stem cells" and the conservation of stem cell pools is what he calls "steadystate stem cells." Thus, steady-state stem cells are cells that maintain homeostasis of the tissues, divide asymmetrically (i.e., they self-renew) and only rarely (i.e., most often they are quiescent); whereas emergent stem cells divide at a high rate and "do not exhibit self-renewal" (Shostak 2006, p. 305).

To conclude, there are different types of stem cells with specific characteristics and behaviors. This classification of stem cells appears suitable for the study of development because the developmental abilities are linked with the types of stem cells (totipotent stem cells are able to give rise to an entire organism whereas unipotent stem cell can only give rise to one type of cells). I will show in more detail the link between stem cell types and developmental capacities in a later section. Moreover, I argue that it is useful for the issue of temporal boundaries of development because the two types of distinctions (i.e., distinctions in potential of differentiation and distinctions in division) are also temporal. "Stem cells at different developmental stages appear to have different capacities for self-renewal and differentiation" (Robert 2004b, p. 1005). This will be the subject of the next section.

\section{Temporal Differential Distribution of Stem Cells}

The different types of stem cells described in the previous section have temporal characteristics. Totipotent stem cells are the first cells of the developing organism: "the fertilized oocytes and the descendants of the first two divisions"; pluripotent stem cells are the cells of "the inner cell mass from which the embryo develops"; multipotent and unipotent stem cells are described as differentiated tissuespecific stem cells (Alison et al. 2002, p. 420), meaningfully, they are also often called "adult stem cells." In the same way, the emergent stem cells mainly refer to the development of the embryo and the steady-state stem cells describe the cells "capable of maintaining adult tissue in the steady state through asymmetric cell division" (Shostak 2006, p. 303).

Strictly speaking, emergent tissues are transient, and cells in emergent populations do not exhibit selfrenewal. Initially, symmetric divisions produce a growing population of cells, and later emergent cell 
populations disappear entirely [...]. Thus, the zygote, blastomeres, founder cells, telomeres, germ layers, and organ rudiments are only temporary parts of developing organisms. Of course, these developing populations are normally replaced by various sorts of steady-state populations, and clonal expansion of developing tissues is replaced by self-renewing (SR) stem cells and lineages of transit amplifying (TA) and differentiating cells. (Shostak 2006, p. 305 [emphasis added])

In this section, I want to analyze more precisely the temporal boundaries of the distinct types of stem cells.

\section{Potentiality}

First, let us consider the differences in the potential of differentiation. The four types of potentiality in stem cell presented earlier (i.e., totipotency, pluripotency, multipotency, and unipotency) indicate three different stages in the life of an organism. The first stage is the totipotent one and it runs from the zygote to the eight cells embryo: "After the third cell division, cells begin to specialize, and an inner cell mass (ICM) forms within the blastocyst. Cells removed from the ICM are pluripotent" (Robert 2004b, p. 1005). This first stage often seems temporally well defined in the scientific literature. However, the eight-cell stage has been criticized for being too rigid. According to Hauskeller, "Embryonic development does not allow for a clear demarcation line and there is no magic jump from an eightto more than eight-cell stage" (Hauskeller 2005, p. 823). She argues that the strong current definition of totipotency and pluripotency derived from ethical and juridical issues. According to her, "this narrow understanding of "totipotency' [from the zygote to the eight cells] was stressed by some scientists in the stem cell debate in order to convince everybody, from the scientific community to the policymakers and the public, that embryonic [pluripotent] stem cell research with existing cell lines is in accordance with the Embryo Protection Act" (Hauskeller 2005, p. 823). Moreover, the distinction applies specifically to organisms whose development requires the production of embryonic annexes (placenta, yolk sac). For other species, there are only two types of stem cells: totipotent or pluripotent (the use of one or the other word varies among biologists) and multipotent (and possibly unipotent).

The second stage, the pluripotent one, then supposedly begins after the third division of the zygote. It is truly difficult to indicate the end of this stage but, in vertebrates, it is widely considered that there are no more pluripotent stem cells after the production of the tissue-specific stem cells. Differentiated and functional tissues are produced and maintained by multipotent/tissue-specific stem cells.
So, there must be a boundary somewhere. There are two problems concerning the end of pluripotency. First, some recent results suggest that even in mammals-the main model to study the transition from pluripotent to multipotent stem cells-there may be pluripotent stem cells in the adult, the mesenchymal stem cells, called MAPC (Jiang et al. 2002). The concept of MAPC is as exciting as it is controversial and the genuine existence of pluripotent stem cell remains hypothetical. Indeed, MAPC is an acronym for "Multipotent Adult Progenitor Cells" that carefully avoids the words "pluripotent" and "stem cell." However, the possibility of persistence of pluripotency must be taken into account. Moreover, for a lot of species, like plants and animals that reproduce by budding (e.g., hydra) or that are capable of a high rate of regeneration (e.g., planarian), the persistence of pluripotent or totipotent stem cells throughout life is highly likely (see Bosch 2008). Second, the transition from pluripotency to multipotency is probably continuous. For example, the multipotent hematopoietic stem cell (i.e., tissue-specific stem cell of the hematopoietic system) comes from a "hemangioblast" which is in between the pluripotent stem cell of the ICM and the multipotent stem cell of the hematopoietic system (Jaffredo et al. 2005; Xiong 2008). Pluripotency is a very elusive stage of stem cells but the difficulty can be partly avoided by determining the boundary between the second and the third stage through the beginning of the third stage, which can be identified with precision.

The third stage indicated by potential of differentiation is that of multi and unipotent stem cells (the tissue-specific stem cells). In a complex organism, there can be a lot of different tissue-specific stem cells. The production of these different tissue-specific stem cells takes time, as it is not a synchronous event. However, for each type of tissue-specific stem cell it must be possible to assign a particular temporal origin. For example, the emergence of hematopoietic stem cells is well known and defined: day E10.5 for the mouse (Dzierzak and Speck 2008), and "Gametogenesis begins with embryonic precursors known as primordial germ cells, which are detected by E7.5 in the mouse. Primordial germ cells differentiate into spermatogonial stem cells in males and oocytes stem cells in females after migrating into the genital ridges at about E12.5" (Molofsky et al. 2004, p. 702). Determining when the first and the last tissue-specific stem cell of an organism emerges would require knowing every tissue-specific stem cell. This is far from being the case. However, this does not mean that there is no boundary between the second and the third period. Instead, in the same way that you can assign a specific period to the emergence of hematopoietic stem cells or spermatogonial and oocytes stem cells, there must be a precise point at which the first and the last type of multipotent stem cells appear. 


\section{Division}

Let us now consider the classification of stem cells through their differences in division. Differences in the rate of division do not have any precise temporal boundaries in Shostak studies, but they clearly indicate two very distinct phases: an embryonical one and an adult one. The question is: When do stem cells stop dividing quickly and begin to be quiescent? The formulation of Shostak has the advantage of being made intuitive by virtue of the causal link identified between the rate and type of division (symetric or asymetric, self-renewal or differentiation) and the system to which they belong (tissue, organ, etc.). Thus, the boundary between these two types of stem cells is the same as the boundary between emergent tissues and steady-state tissues. However, much more accurate data are needed to account for these differences in the states of stem cells.

The studies of Morrison are more informative regarding the temporal boundary between emergence and steadystate, at least for some species: "mammalian stem cells seem to make a developmentally regulated transition from largely symmetric to predominantly asymmetric divisions during mid to late gestation"; "For example, both neural and epidermal progenitors change from primarily symmetric divisions that expand stem-cell pools during embryonic development to primarily asymmetric divisions that expand differentiated cell numbers in mid to late gestation" (Morrison and Kimble 2006, p. 1071; see also Morrison et al. 1995). Morrison is one of very few biologists who examine the molecular differences between stem cells over time. He identified some "key age-specific mechanisms" linked to stem cell division (Levi and Morrison 2008): Bmi-1, for example, is only required in postnatal stem cells, whereas Nanog and Oct4 regulate the maintenance of pluripotency in ES cells and epiblast cells but are not required for the function of fetal or adult somatic stem cells, "Nanos3 and Nanos 2 are dispensable for the specification of primordial germ cells but are sequentially required for the maintenance of germ-line stem cells during development" (541), "Gfi1, Tel/Etv6, FoxO gene products are all required for the maintenance of adult but not fetal HSCs" (544), "Fetal and neonatal HSCs have a unique self-renewal program that depends on the Sox17 transcriptional regulator" (542) (for other differences, see also Molofsky et al. 2004).

Like the transition from the pluripotent stage to the multipotent stage, the transition is continuous between the emergent and the steady-state stages. However, in contrast with the potential of differentiation, which is considered irreversible in vivo, the rate of division is more variable and can change over time. As noted by Morrison: "Although some adult stem cells seem to divide asymmetrically under steady-state conditions, they retain the capacity to divide symmetrically to restore stem-cell pools depleted by injury or disease, as has been observed in the nervous and haematopoietic systems" (Morrison and Kimble 2006, p. 1071). An injured tissue may recruit its stem cells to restore itself. In those cases, some of the steady-state stem cells revert to an emergent state (for example, in mice, see Morrison et al. 1997; Wright et al. 2001). In vertebrates, these reversions of stem cells are rare in quantity. They do not affect the existence of two distinct stages, the first defined by emergence, the second by its stability. However, in other species, such as planarians or annelids, which are able to regenerate whole organs, the reversibility of stem cells seems more important. For theses species, the existence of two distinct stages is not so clear.

In summary, classifications of stem cell types can exhibit strong temporal organization: different types of stem cells for different stages of life. While examining these temporal distributions of stem cell types, I also highlighted a variability between species: Some species lack distinctions between totipotency and pluripotency (i.e., species without extraembryonic annex), some species retain pluripotent stem cells all their life, some species can highly reverse the rate and type of division of their stem cells. I will now consider these differences among species.

\section{The Temporal Boundaries of Development are Species-Dependent}

The above classifications of stem cells suggest that the differential temporal distribution of stem cell types can change from one species to another. The criterion of stem cell has a particular interest: It provides the means to highlight the temporality of development in any organism. In particular, the great strength of the stem cell criterion is that it can in itself account for very heterogeneous developmental processes. Indeed, the differences between stem cells' temporal organizations highlight four distinct categories in which development presents temporal differences. This section presents these different patterns. They are all summarized in Table 1.

\section{TDP (A): Three Phases}

As discussed in the previous section, species with extraembryonic annexes present four types of stem cells (totipotent, pluripotent, multipotent, and unipotent stem cells) organized in three phases. The first phase is characterized by totipotent stem cells (Tp-SC) and runs from the one- to the eight-cells stage. The second phase is characterized by pluripotent stem cells (Pp-SC) and runs from the eight-cells stage to the emergence of the last type of tissue-specific 
Table 1 Patterns of temporal distributions of the different types of stem cells

\begin{tabular}{|c|c|c|c|c|}
\hline & $\begin{array}{l}\text { TDP (A) } \\
3 \text { phases }\end{array}$ & $\begin{array}{l}\text { TDP }(B) \\
2 \text { phases }\end{array}$ & $\begin{array}{l}\text { TDP }(C) \\
1 \text { phase }\end{array}$ & $\begin{array}{l}\text { TDP (D) } \\
\text { Alternating phases }\end{array}$ \\
\hline Number of stem cell types & $\begin{array}{l}4 \text { types of SC: } \\
-\mathrm{Tp}-\mathrm{SC} \\
\text {-Pp-SC, } \\
\text {-Mp-SC, } \\
\text {-Up-SC }\end{array}$ & $\begin{array}{l}3 \text { types of SC: } \\
\text { No differences between } \\
\text { Tp-SC and Pp-SC }\end{array}$ & $\begin{array}{c}\text { Unknown and/ } \\
\text { or irrelevant }\end{array}$ & $\begin{array}{l}\text { At least } 2 \text { types of SC: } \\
-\mathrm{Tp} / \mathrm{Pp}-\mathrm{SC} \\
-\mathrm{Mp} / \mathrm{Up}-\mathrm{SC}\end{array}$ \\
\hline $\begin{array}{l}\text { Temporal distributions } \\
\text { of stem cell types }\end{array}$ & $\begin{array}{l}\text { Succession } \\
\text {-phase 1: } \\
\text { Tp-SC; } \\
\text {-phase 2: } \\
\text { Pp-SC; } \\
\text {-phase 3: } \\
\text { Mp/Up-SC }\end{array}$ & $\begin{array}{l}\text { Succession } \\
\text {-phase 1: } \\
\text { Tp/Pp-SC; } \\
\text {-phase 2: } \\
\text { Mp/Up-SC }\end{array}$ & $\begin{array}{l}\text { Persistence } \\
\text { of Tp/Pp-SC }\end{array}$ & Dedifferentiation \\
\hline Species examples & Mouse & Nematode & Hydra & Axolotl \\
\hline
\end{tabular}

$T D P$ temporal developmental pattern; $T p-S C$ totipotent stem cells; $P p-S C$ pluripotent stem cells; $M p$-SC multipotent stem cells; $U p$-SC unipotent stem cells

stem cell. The end of this second phase must still be precisely determined. According to current knowledge, it should be situated during the embryonic period. The third stage is characterized by multipotent and unipotent stem cells (Mp- and Up-SC) and runs from this still-to-bedetermined emergence of tissue-specific stem cell to the death of the organism. Mice and humans are good examples of this TDP [cf. Table 1, TDP (A)].

\section{TDP (B): Two Phases}

Species that do not need extraembryonic annexes to develop do not allow the separation between the first and the second phases. Among these species, stem cell types are organized in two stages. The first phase corresponds to the first and second phases previously described [in the TDP (A)]. It runs from the egg to the still-to-be-determined emergence of the tissue-specific stem cells. The second phase lasts the rest of the life. Nematodes are examples of this TDP [cf. Table 1, TDP (B)].

\section{TDP (C): One Phase}

For some species, the emergence of tissue-specific stem cells does not allow for distinguishing two distinct phases because they maintain totipotent or pluripotent stem cells throughout their lives. This is related to the possession of particular capabilities: forms of regeneration and asexual reproduction. Both are very important processes for the study of development.
First let us look in more detail at regeneration. Regeneration is intimately linked to the capacity of generation of organs or even organisms. As shown by Vervoort (2011, this issue), regeneration is a concept used very flexibly (see Morgan 1901). Indeed, since Morgan and still today, biologists have been trying to distinguish the different types of regeneration. These distinctions are crucial for the question of development because ability to produce a new organ, like a limb after amputation, is very distinct from the ability to renew cells throughout life.

Stripped of specialized functions, and reduced to its most fundamental property, i.e., the restoration of bodily components, regeneration becomes the equivalent of physiological maintenance. This is an obligatory task performed by all organisms in order to survive and thrive against the constant and generally disruptive forces of nature. (Sánchez Alvarado 2000, p. 583)

As early as 1901, Morgan proposed distinguishing two types of regeneration: the "physiological regeneration" and the "restorative regeneration." This distinction is still relevant and very similar to the recent distinction made by Poss (2010) between what he calls "homeostatic regeneration" in reference to the natural replacement of cells lost in day-to-day minor damage, cell death, and aging; and what he calls "facultative regeneration" (or "injuryinduced regeneration") in reference to tissue replacement after substantial trauma like amputation or ablation. Organisms that can only perform "physiological" (Morgan) or "homeostatic" (Poss) regeneration can produce their organs only once, and then maintain them. After amputation a mammal cannot reproduce its lost limb, 
which means that it has lost its original capacity to develop them. By contrast, organisms capable of "restorative" (Morgan) or "facultative" (Poss) regeneration, like salamanders or planarians, can develop their limbs again and again. Thus, species possess very distinct developmental capacities depending on their regenerative potential. In this regard, stem cells are very useful because they allow the distinction between these regenerative capacities to be made. Indeed, it is precisely the systemic function (Cummins 1975) of multipotent and unipotent tissue-specific stem cells to maintain their tissues by physiologicalhomeostatic regeneration and of pluripotent or totipotent to generate, or regenerate by restorative-facultative regeneration, whole organs. Consequently, physiological-homeostatic regeneration does not affect the TDPs previously described: Organisms only capable of physiologicalhomeostatic regeneration possess totipotent/pluripotent stem cells only during the first period of their life. By contrast, restorative-facultative regeneration requires a high potential for differentiation and a high recruitment of stem cells (Sánchez Alvarado 2000). Thus, organisms that perform facultative-restorative regeneration during their life possess stem cells described in the previous TDP as specific to the embryonic period (see Salo 2006). Consequently, those organisms present a different TDP compared to those described earlier [TDP (A) and (B)] and the persistence of pluripotent or totipotent stem cells do not allow for making the distinction between phases.

Asexual reproduction, the capacity of one organism to produce a new organism, can also be an important matter for development. More precisely, two different types of reproduction are usually distinguished: sexual and asexual reproduction. Only some species present a capacity for asexual reproduction. However, as regeneration, asexual reproduction encompasses very different phenomena including processes as diverse as fission, budding, fragmentation, parthenogenesis, apomixes, vegetative reproduction, or mitotic sporogenesis. Among these, not all are relevant to temporal distinctions in development. Organisms reproducing without any male gamete do not necessarily present differences in the temporality of their development, as in the cases of parthenogenesis and apomixes (i.e., when unfertilized eggs can develop). Bees, for example, can reproduce either sexually or asexually (by parthenogenesis). In both cases, the temporality of the development of the mother and of the newborn bee is pretty much the same as for any organism of the TDP (A): They present a first stage of organogenesis and then a stage of maintenance throughout their life. However, several types of asexual reproduction like budding or fragmentation require capacities similar to facultative regeneration, that is, the capacity to produce new organs during their life (see Brockes and Kumar 2008). As noticed by Sánchez
Alvarado, « in those organisms whose parts are capable of regenerating entire individuals, their asexual mode of reproduction (budding in hydra, and fission in planarians, for instance) is indistinguishable from their [...] modes of regeneration » (2000, p. 583). Indeed, planarians have such great regenerative capacities that they can reproduce every part of their body. Thus, when a planarian is cut in two, it gives rise to two planarians, each part of the body reproducing the missing part. This regenerative phenomenon is, therefore, also a case of asexual reproduction, given that new organisms are produced. This example perfectly illustrates the process of asexual reproduction by fragmentation: An organism splits and the fragments develop into new entire organisms (for another example, the starfish, see Hughes 1989). Similarly, budding is an asexual mode of reproduction that requires the capacity to produce a new organ: Budding is a process through which a new organism grows on an existing organism, as if it was a new organ. The freshwater polyp Hydra, for example, can reproduce by budding. The developing Hydra only separates from the body of the parental Hydra when it has reached its mature form. A similar phenomena is known in some plants, like Kalanchoe: "Plantlets develop symmetrically along the leaf margins on leaf notches, closely resembling zygotic embryos in development, and once the root system is formed, they detach from the mother-leaf, fall to the ground, and grow into new plants" (Garces and Sinha 2009). In all these cases, the asexual reproductions are performed through totipotent or pluripotent stem cells. As for regeneration, some forms of asexual reproduction involve conservation of totipotent or pluripotent stem cells. This persistence of totipotent/pluripotent stem cells does not allow for distinct phases to be identified during the life of those organisms [cf. Table 1, TDP (C)].

\section{TDP (TDP) (D): Alternating Phases}

The previous developmental capacities involving totipotent/pluripotent stem cells during adulthood can be performed either by conservation of those totipotent/ pluripotent stem cells during the life or by dedifferentiation at particular periods.

In these organisms [such as salamanders], which are capable of regenerating missing body parts such as their limbs and tail, no reserve of pluripotential cells is to be found in the normal, uninjured appendages. Instead, the pluripotential cells are produced de novo from pre-existing, terminally differentiated cells. After injury or amputation, the cells of this animal first have to undergo a process of dedifferentiation, then re-enter mitosis and proliferate before a source 
of pluripotential cells is available to regenerate the missing appendage. (Sánchez Alvarado 2000, p. 585)

In these cases, organisms can develop during their entire life but they also do present distinct phases: They alternate phases of generation or regeneration characterized by proliferating totipotent/pluripotent stem cells and phases of maintenance characterized by multipotent/unipotent stem cells during their entire life [cf. Table 1, TDP (D)].

In conclusion, this section highlights the variability of the temporality of development among species. The particular interest of the use of stem cells is that it allows for taking into account the diversity among species while also exhibiting more general patterns. Indeed, four types of temporality are sufficient to account for this diversity. These four types can be classified more generally into two groups: species with high developmental properties restricted to one single period of their lives [either with-TDP (A) - or without-TDP (B) - the development of extraembryonic annexes] and species with high developmental properties persisting throughout their life [either constantly-TDP (C)-or alternately-TDP (D)]. This section has also demonstrated the pertinence of the stem cells tool: It can account for very heterogeneous processes. The temporality of development varies among species depending on different abilities such as different types of regeneration and of asexual reproduction. In regard to the complexity of these processes (which, besides, overlap), stem cells have been shown to be a much simpler and effective criterion in the analysis of the temporality of development.

\section{Looking for the Temporal Boundaries of Development?}

Now, the question is whether these patterns highlight different temporal boundaries of development or just different stages within development. Unfortunately, as explained in the first section of this article, this question cannot be answered on the basis of biological data because of the vagueness of the definition of development. The interpretation of these data directly relies on the perspective that one chooses to take on the question of the definition of development. You will remember that I presented three options: (1) to eliminate the concept of development, (2) to harden its definition, or (3) to keep the current fuzzy definition of development but within a binominal perspective adding "specific" qualifiers that allow the identification of a concrete referential.

The first option (i.e., to get rid of the concept of development) may be interesting but is of no value for the consideration of the temporality of development.

The second option (i.e., to harden the definition of development) would lead to considering only one type of the phases described in the TDPs as developmental, that is, the phase characterized by emergent pluripotent stem cells (Pp-SC). This option would be of great interest for two reasons. The main reason is that the resulting temporal boundaries of development would directly put forward the differences between species: Mouse only develops for a restricted embryonic period of its life whereas Hydra develops during its entire life, and so on for every species. The second benefit of this option is that it would actually produce a much more precise definition of development: Development is the ability to produce (and not just to maintain) a full functional organ. However, this advantage would also be debated. Indeed, given that in this second option, multipotent and unipotent stem cells are excluded from the definition of development, growth is also excluded from the properties that are characteristic of development.

The third option deserves more attention because it is the most likely to be implemented given that the concept of development is a boundary concept. Therefore, I propose exploring it a little further. The need for definitions sufficiently broad and flexible for boundary concepts often conflicts with the need for more stringent definitions in specific theoretical or disciplinary frameworks (on the need for stringent definitions, see Pradeu 2009). However, according to my work, combining the existence of fuzzy concepts with the production of specific qualifiers that allow identification of a concrete referential is possible. Burian (2005, p. 166) distinguishes two kinds of definitions in the case of the gene concept. The first one is "generic" or "schematic" and its referential is indefinite, that is, these kinds of definitions "do not suffice for specifying the reference of the term." Burian (2005, p. 167) describes generic concepts as "descriptions that leave the exact referent of the term open," which has the advantage of allowing several possibilities for this referential. The second kind of definition of concepts described by Burian is "specific" or "discontinuous." These definitions are much more precise and solve the problem of the referential but at the cost of a conceptual discontinuity. According to him, "what counts as a gene is thoroughly contextdependent" and "this has the consequence that precise definitions of genes must be abandoned, for there are simply too many kinds of genes" (p. 175). Contrary to the conclusion he draws, in the case of development, I see no contradiction in the coexistence of one "generic" definition of the concept of development and many "specific" and "discontinuous" definitions specifying the referential that the author has in mind. In my mind this could even be the most satisfactory solution to the problem of the definition of development: It would not require the dismissal of the concept of development and it would enable discontinuous and discrete works of specification on the definitions of development, which would in turn enable authors to clarify what they mean when they talk about development. 
This third option (i.e., adding specific qualifiers to the current concept of development) would lead to considering the distinct phases as distinct types of development. This binominal perspective leaves open the classification of development types: One could define a regenerative development, a reproductive development, a physiological development, and so on. However, this article shows that stem cells are a good ubiquitary criterion summarizing the developmental capacity of the system to which they belong (organisms, but also organs and tissues). Thus, I propose using the classification of stem cells to distinguish distinct types of development. This leads to the four following categories of development: totipotent development, pluripotent development, multipotent development, and unipotent development. Regarding the issue of the temporal boundaries of development, there is a major argument in favor of this classification of development types: It still allows for a species-specific description of the temporality of development, even if this description would be far less perceptible than if we chose to harden the definition of development (second option). Indeed, as shown in the previous section, the same phase has different temporal boundaries from one species to another.

\section{Conclusion}

This article stands against both the RB thesis (i.e., development ends at reproductive maturity) and the DB thesis (i.e., development lasts throughout life) primarily because neither of them reflects the differences between species in the temporality of their development. Indeed, this article intends to develop a new species-dependent perspective on temporal boundaries of development. In this perspective, stem cells were used to exhibit the different developmental capabilities both in time and between species. They enabled four TDPs to be characterized, that is, four ways in which development occurs in distinct species. These can be interpreted differently depending on the perspective one has on the definition of development.

When assuming that the definition of development should be hardened I suggested a new definition of development: Development is the ability to produce (and not just to maintain) a full functional organ. This leads to the identification of species-dependent temporal boundaries of development: Development ends with the loss of pluripotent stem cells; for some species, it is very early within the life of the organism (likely prenatal), for others it is by alternation because the loss is not final; some species also never lose their pluripotent stem cells. Thus, within this framework, the DB thesis is valid for some species but not for all and the RB thesis never applies.
By contrast, in the context of the current (non)definition of development, the TDPs support the DB thesis in its weak interpretation (i.e., development is a complex and heterogeneous phenomenon that involves a set of various mechanisms and processes occurring by stages throughout life) and in its strong interpretation (i.e., development only ends with death because the same mechanisms and processes last throughout life) for some species, that is for species in which pluripotent or totipotent stem cells persist throughout life. However, they contradict the strong interpretation of the DB thesis for other species because strong distinctions are made between different periods of life. In this context, I suggested a characterization of different developmental abilities to be able to give a speciesdependent account of the temporality of development. I suggested distinguishing totipotent development, pluripotent development, and multipotent development. This allows for putting forward species-specific temporal boundaries of these types of development (instead of boundaries of development in general).

Acknowledgments I am grateful to Michel Morange, Antonine Nicoglou, Thomas Pradeu, Frédérique Théry, and Michel Vervoort for the collective work that we have done together and for the critical reading of this manuscript. I am also thankful to Bernadette Bensaude-Vincent, Jean Gayon, Thierry Hoquet, Jane Maienschein, and Francesca Merlin for their critical reading of the manuscript. I address a special thanks to Thierry Hoquet for formulating development as "le temps qui traverse les corps" ("the time which passes through the body"), a formulation that has greatly influenced the articulation of this article around the TDPs. Finally, I want to thank Charles Durand, Jean Gayon, Thierry Hoquet, Thierry Jaffredo, Francesca Merlin, and Valérie Ngo-Muller for useful discussions. My work is supported by the Cancéropôle and the University Paris Ouest Nanterre La Défense.

\section{References}

Alison MR, Poulsom R, Forbes S, Wright NA (2002) An introduction to stem cells. J Pathol 197(4):419-423

Blau HM, Brazelton TR, Weimann JM (2001) The evolving concept of a stem cell: entity or function? Cell 105(7):829-841

Bosch TCG (2008) Stem cells: from hydra to man. Springer, Dordrecht

Brockes JP, Kumar A (2008) Comparative aspects of animal regeneration. Annu Rev Cell Dev Biol 24:525-549

Burian R (2005) Too many kinds of genes. Some problems posed by discontinuities in gene concepts and the continuity of the genetic material. In: Burian R (ed) The epistemology of development, evolution, and genetics. Cambridge University Press, Cambridge, pp 166-178

Crist E, Tauber AI (1999) Selfhood, immunity, and the biological imagination: the thought of Frank Macfarlane Burnet. Biol Philos 15(4):509-533

Cummins R (1975) Functional analysis. J Philos 72:741-765

Dzierzak E, Speck NA (2008) Of lineage and legacy: the development of mammalian hematopoietic stem cells. Nat Immunol 9(2):129-136 
Garces H, Sinha N (2009) The "mother of thousands" (Kalanchoe daigremontiana): a plant model for asexual reproduction and CAM studies. Cold Spring Harb Protoc 2009(10):133

Hauskeller C (2005) Science in touch: functions of biomedical terminology. Biol Philos 20:815-835

Hughes RN (1989) A functional biology of clonal animals. Chapman and Hall, London

Jaffredo T, Bollerot K, Sugiyama D, Gautier R, Drevon C (2005) Tracing the hemangioblast during embryogenesis: developmental relationships between endothelial and hematopoietic cells. Int J Dev Biol 49(2-3):269-277

Jiang Y, Jahagirdar BN, Reinhardt RL, Schwartz RE, Keene CD, Ortiz-Gonzalez XR, Reyes M, Lenvik T, Lund T, Blackstad M, Du J, Aldrich S, Lisberg A, Low WC, Largaespada DA, Verfaillie CM (2002) Pluripotency of mesenchymal stem cells derived from adult marrow. Nature 418:41-49

Lander AD (2009) The "stem cell" concept: is it holding us back? J Biol 8:70

Laubichler MD, Maienschein J (2005) Development. In: Horowitz MC (ed) New dictionary of the history of ideas. Thomson Gale, Detroit, pp 570-574

Levi BP, Morrison SJ (2008) Stem cells use distinct self-renewal programs at different ages. Cold Spring Harb Symp Quant Biol 73:539-553

Leychkis Y, Munzer SR, Richardson JL (2009) What is stemness? Stud Hist Philos Biol Biomed Sci 40(4):312-320

Loeffler M, Roeder I (2002) Tissue stem cells: definition, plasticity, heterogeneity, self-organization and models-a conceptual approach. Cells Tissues Organs 171(1):8-26

Love A (2006) Taking development seriously: who, what, when, where, why, how? Biol Philos 21:575-589

Löwy I (1991) The immunological construction of the self. In: Tauber AI (ed) Organism and the origins of self, 3-75. Kluwer: Boston Studies in the Philosophy of Science, Dordrecht

Löwy I (1992) The strength of loose concepts-boundary concepts, federative experimental strategies and disciplinary growth: the case of immunology. Hist Sci 30:371-395

Marks NJ (2010) Defining stem cells? Scientists and their classifications of nature. Sociol Rev 58(s1):32-50

Mikkers H, Frisen J (2005) Deconstructing stemness. J Eur Mol Biol Organ 24:2715-2719

Molofsky AV, Pardal R, Morrison SJ (2004) Diverse mechanisms regulate stem cell self-renewal. Curr Opin Cell Biol 16:700-707

Morgan TH (1901) Regeneration. Macmillan Company, New York

Morrison SJ, Kimble J (2006) Asymmetric and symmetric stem-cell divisions in development and cancer. Nature 441(7097): 1068-1074

Morrison SJ, Hemmati HD, Wandycz AM, Weissman IL (1995) The purification and characterization of fetal liver hematopoietic stem cells. Proc Natl Acad Sci USA 92:10302-10306

Morrison SJ, Wright DE, Weissman IL (1997) Cyclophosphamide/ granulocyte colony-stimulating factor induces hematopoietic stem cells to proliferate prior to mobilization. Proc Natl Acad Sci USA 94:1908-1913
Poss KD (2010) Advances in understanding tissue regenerative capacity and mechanisms in animals. Nat Rev Genet 11(10): $710-722$

Pradeu T (2009) Les limites du soi: Immunologie et identité biologique. Vrin, Montreal

Pradeu T (2011) A mixed self: the role of symbiosis in development. Biol Theory 6(1). doi:10.1007/s13752-011-0011-5

Rheinberger H-J (2000) Gene concepts: fragments from the perspective of molecular biology. In: Beurton PJ, Falk R, Rheinberger H-J (eds) The concept of the gene in development and evolution: historical and epistemological perspectives. Cambridge University Press, Cambridge, pp 219-239

Robert JS (2002) How developmental is evolutionary developmental biology. Biol Philos 17:591-611

Robert JS (2004a) Embryology, epigenesis, and evolution: taking development seriously. Cambridge University Press, New York

Robert JS (2004b) Model systems in stem cell biology. Bioessays 26(9):1005-1012

Salo E (2006) The power of regeneration and the stem-cell kingdom: freshwater planarians (Platyhelminthes). Bioessays 28(5): 546-559

Sánchez Alvarado A (2000) Regeneration in the metazoans: why does it happen? Bioessays 22(6):578-590

Seaberg RM, van der Kooy D (2003) Stem and progenitor cells: the premature desertion of rigorous definitions. Trends Neurosci 26(3):125-131

Shostak S (2006) (Re)defining stem cells. Bioessays 28(3):301-308

Star SL, Griesemer JR (1989) Institutional ecology, "translations" and boundary objects: amateurs and professionals in Berkeley's Museum of Vertebrate Zoology, 1907-39. Soc Stud Sci 19(4): $387-420$

Théry F (2011) Characterizing animal development with genetic regulatory mechanisms. Biol Theory. doi:10.1007/s13752-0110004-4

Vervoort M (2011) Regeneration and development in animals. Biol Theory. doi:10.1007/s13752-011-0005-3

Wright DE, Cheshier SH, Wagers AJ, Randall TD, Christensen JL, Weissman IL (2001) Cyclophosphamide/granulocyte colonystimulating factor causes selective mobilization of bone marrow hematopoietic stem cells into the blood after M phase of the cell cycle. Blood 97:2278-2285

Xiong JW (2008) Molecular and developmental biology of the hemangioblast. Dev Dyn 237:1218-1231

Zipori D (2004) The nature of stem cells: state rather than entity. Nat Rev Genet 5(11):873-878

Zipori D (2005) The stem state: plasticity is essential, whereas selfrenewal and hierarchy are optional. Stem Cells 23(6):719-726

Zipori D (2006) The stem state: mesenchymal plasticity as a paradigm. Curr Stem Cell Res Ther 1(1):95-102

Zipori D (2009) Biology of stem cells and the molecular basis of the stem state. Humana Press, Dordrecht 